\title{
Interpeduncular Cistern
}

National Cancer Institute

\section{Source}

National Cancer Institute. Interpeduncular Cistern. NCI Thesaurus. Code C32866.

A cavity within the subarachnoid space between the two temporal lobes and in front of the pons. 